\title{
Influência do uso precoce de antibiótico na saúde de bezerras Holandesas durante o período neonatal
}

Camila Cecilia Martin, Camila Costa Baccili, Taís Pinheiro de Carvalho, Natália Meirelles Sobreira, Jean Ramos Silva, Karen Nascimento da Silva, Nathália Decaris, Viviani Gomes

Faculdade de Medicina Veterinária e Zootecnia, Universidade de São Paulo (USP), São Paulo, SP, Brasil

*Autor correspondente

e-mail: viviani.gomes@usp.br

\section{Resumo}

O uso precoce de antibióticos tem sido adotado para diarreias e doença respiratória na criação de bezerras, no entanto, existem controvérsias se esta prática tem efeito benéfico. 0 objetivo desta pesquisa foi avaliar a influência do uso precoce de antibiótico na saúde das bezerras no período neonatal. Foram utilizadas 26 bezerras hígidas, de raça Holandesa, distribuídas em dois grupos experimentais compostos por 13 animais: $\mathrm{ATB}+=$ bezerras que receberam uma dose de antibiótico ao nascimento (Tulatromicina, dose 2,5 mg/Kg, SC); e ATB- = bezerras que receberam uma dose de solução fisiológica ao nascimento (1 mL, SC). As bezerras foram examinadas por meio de exame clínico geral e sistema de escores padronizado pela Universidade de Wiscosin-Madison. Além disso, a região umbilical foi avaliada para a detecção de alterações inflamatórias localizadas no umbigo externo. Foram colhidas amostras de sangue para realização de hemograma, ferro (Ferro UIBC, Randox ${ }^{\circledR}$ ) e dosagem de haptoglobina (espectrofotometria). Os animais foram avaliados nos seguintes momentos: até $12 \mathrm{~h}$ após o nascimento (M1), 3-5ํ dia de vida (M2), 7-9 ${ }^{\circ}$ (M3), $13^{\circ}-15^{\circ}$ (M4), 20-23 dia (M5) e 27-30 dias pós-nascimento (M6). Os dados quantitativos foram analisados pela ANOVA para medidas repetidas, seguida do teste de Tukey. Dados qualitativos foram comparados pelo teste de Qui-quadrado. As análises foram consideradas significativas quando $\mathrm{P} \leq 0,05$. Não foi possível observar alterações no exame clínico geral em nenhum dos grupos. Em relação à coloração das mucosas, detectou-se uma tendência de bezerras com mu cosas rósea claras ou esbranquiçadas no M3 no grupo ATB- ao nascimento $(23,1 \%)$, em relação ao grupo ATB + $(0,00 \%)(P=0,066)$. A frequência de diarreias foi de 15,4 e $7,7 \%$ no $M 1$, 23,1 e 15,4\% no M2, 15,4 e 30,8\% no M3, 92,8 e 92,8\% no M4, 23,1 e 15,4\% no M5 e 7,7 e 30,8\% nos grupos ATB- e ATB+, respectivamente. Não foi possível detectar diferença entre os grupos. Em relação às alterações umbilicais, detectou-se maior frequência no grupo ATB- no M2 (ATB- 38,5\%; ATB+ 7,7\%, P=0,063) e M4 (ATB- 23,1\%; ATB+ 0,0\%, P = 0,066). A frequência de broncopneumonia foi semelhante em ambos os grupos. 
Em relação ao eritrograma, observamos uma tendência $(p=0,071)$ no valor da hemoglobina $(A T B+=9,33$ $\pm 2,29 \mathrm{~g} / \mathrm{dL}$; ATB-= 8,06 $\pm 2,35 \mathrm{~g} / \mathrm{dL})$ e concentração de hemoglobina corpuscular média $(\mathrm{P}=0,057)(\mathrm{ATB}+$ $=33,74 \pm 1,10 \mathrm{~g} / \mathrm{dL}$; ATB- $=32,80 \pm 1,29 \mathrm{~g} / \mathrm{dL}$ ) no M2. 0 teor de ferro variou de 3,9 a $14,44 \mu \mathrm{M} / \mathrm{L}$ no ATB- e 3,95 a 15,06 $\mu \mathrm{M} / \mathrm{L}$ no ATB+, sendo possível observar menores teores no ANT- em M2 (P = 0,051). A concentração de haptoglobina foi maior no ATB + (1,31 $\pm 0,86 \mathrm{mg} / \mathrm{dL})$ em relação ao ATB- $(0,81 \pm 0,23$ $\mathrm{mg} / \mathrm{dL})$ no $\mathrm{M} 4(\mathrm{P}=0,032)$. Conclui-se que o uso de antibiótico não influenciou na prevalência de diarreia e broncopneumonia, porém detectou-se menor frequência das inflamações umbilicais e suas consequências no grupo ATB+ nos momentos que coincidia com o pico de ação da tulatromicina equivalente a 90 horas. 